\title{
Clinical and Humoral Determinants of Congestion in Heart Failure: Potential Role of Adiponectin
}

\author{
Luca Monzo a, b Martin Kotrc $^{a}$ Jan Benes ${ }^{a}$ Kamil Sedlacek $^{a}$ \\ Ivana Jurcova $^{a}$ Janka Franekova ${ }^{c}$ Petr Jarolim ${ }^{d}$ Josef Kautzner ${ }^{a}$ \\ Vojtech Melenovsky ${ }^{a}$ \\ aDepartment of Cardiology, Institute of Clinical and Experimental Medicine, Prague, Czech \\ Republic; ${ }^{b}$ Department of Cardiovascular, Respiratory, Nephrological, Anaesthetic and \\ Geriatric Sciences, "Sapienza" University, Rome, Italy; 'Department of Laboratory Methods, \\ Institute of Clinical and Experimental Medicine, Prague, Czech Republic; ${ }^{d}$ Department of \\ Pathology, Brigham and Women's Hospital, Harvard Medical School, Boston, MA, USA
}

\section{Keywords}

Heart failure $\cdot$ Congestion · Adiponectin $\cdot$ Right ventricular dysfunction

\begin{abstract}
Background: Some patients with heart failure (HF) are more prone to systemic congestion than others. The goal of this study was to identify clinical and humoral factors linked to congestion and its prognostic impact in HF patients. Methods: A total of 371 advanced HF patients underwent physical examination, echocardiography, right heart catheterization, blood samplings, and Minnesota Living with HF Questionnaire. Subjects were followed-up for adverse events (death, urgent transplantation, or assist device implantation without heart transplantation). Results: Thirty-one percent of patients were classified as prone to congestion. During a median follow-up of 1,093 days, 159 (43\%) patients had an adverse event. In the Cox analysis, the congestion-prone (CP) status was associated with a $43 \%$ higher event risk. The CP status was strongly $(p<0.001)$ associated with body weight loss, right ventricular dysfunction (RVD), dilated inferior vena cava (IVC), diuretics, and beta-blockers prescription and the majority of tested hormones in the univariate analysis. In the multivariate analysis, the only independent variables associated with the CP status were adiponectin, albumin, IVC diameter, and RVD. Adiponectin by itself was predictive of adverse events. In a multivariate model, CP status was no longer predictive of adverse events, in contrast to adiponectin. Conclusions: $\mathrm{CP}$ patients experienced more severe symptoms and had shorter survival. Potential role of adiponectin, a new independent predictor of CP status, should be further examined.
\end{abstract}




\section{Kidney \\ Blood Pressure \\ Research}

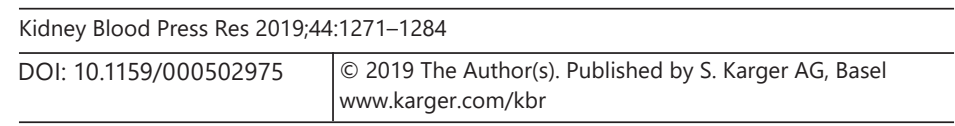

Monzo et al.: Adiponectin in Congestive HF

\section{Introduction}

Congestion, one of the defining components of heart failure (HF) syndrome, is responsible for symptoms, morbidity, and hospitalizations of patients with chronic HF [1]. Achieving and maintaining adequate decongestion is thereby critical prerequisite for long-lasting, event-free management of patients with HF [2].

Although signs and symptoms of congestion are typically present in acutely decompensated HF, some patients experience certain degree of congestion also in clinically stable phases. The reasons why some HF subjects tend to be more prone to congestion, while others suffer more from low cardiac output, are poorly understood. The tendency to develop congestion may reflect inadequate diuretics dosage or intrinsic patient characteristics, such as worse hemodynamic, more renal dysfunction, lower oncotic pressure, more profound renin-angiotensin system activation, or involvement of other humoral systems promoting water retention. Conclusions from previous studies examining congestion determinants are limited because they focused more on acutely decompensated patients [3] or on subjects not exposed to intense neurohumoral blockade [4] that is now widely used in HF population. Deciphering the reasons for higher predisposition to congestion may be clinically relevant, because it may help to design complemental strategies beyond simple loop diuretic titration.

The goal of this study was to identify clinical, hemodynamic, and humoral factors associated with the presence of congestion-prone (CP) status in an advanced electively hospitalized HF cohort with extensive laboratory and clinical phenotyping and follow-up.

\section{Materials and Methods}

The study enrolled patients with chronic ( $>6$ months) advanced systolic HF (ejection fraction $<40 \%$ ) electively hospitalized at a nonintensive care unit ward at the Institute for Clinical and Experimental Medicine in Prague between November 2007 and August 2011 for consideration of heart transplant, cardiac defibrillator (ICD), or cardiac resynchronization therapy implantation. Patients with acute HF decompensation, hemodynamic instability, or reversible cardiac dysfunction (e.g., planned valve surgery, revascularization, tachycardiainduced cardiomyopathy), active malignancy, chronic infection, history of intentional weight loss attempts in the past year, or those unwilling to participate were excluded. The study was conducted according to the Declaration of Helsinki and was approved by the local Ethical Committee. All patients signed written informed consent.

All subjects underwent morning fasting blood sampling for laboratory analysis, medical history, Minnesota Living with HF questionnaire (MLHFQ), and an anthropometric and echocardiography examination (Vivid7, General Electric Healthcare, Wauwatosa, WI, USA). Left ventricular (LV) function and dimensions were measured according to contemporary recommendations [5]. Mitral and tricuspid regurgitation was assessed semiquantitatively and expressed in 3 grades (absent/mild, moderate, and severe). Right ventricular (RV) systolic pressure was estimated from the tricuspid regurgitation velocity (available in $75 \%$ of patients) and right atrial pressure (RAP) estimate, based on inferior vena cava (IVC) diameter. RV dysfunction was quantified (0-3) in an apical 4-chamber view by using tricuspid annular systolic excursion (M-mode TAPSE) and tissue systolic velocity $(\mathrm{Sm})$ as done before [6]. Body weight (BW) was measured by using an electronic scale (HBF-510W, Omron, Japan). BW during the 6-month period before the evaluation was carefully ascertained by subjects' historical recollection and by review of available medical records, as done previously [6, 7]. Right heart catheterization was performed in a subgroup of subjects $(n=175)$ via jugular access using a 


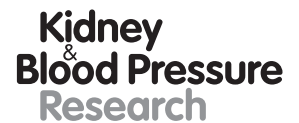

Kidney
Blood Pressure
Research \begin{tabular}{l|l}
\hline Kidney Blood Press Res 2019:44:1271-1284 \\
\hline DOI: 10.1159/000502975 & $\begin{array}{l}\text { @ 2019 The Author(s). Published by S. Karger AG, Basel } \\
\text { www.karger.com/kbr }\end{array}$ \\
\hline
\end{tabular}

Monzo et al.: Adiponectin in Congestive HF

balloon-tipped thermodilution catheter (Corodyn, Braun, Melsungen, Germany) and a standard data acquisition system (MacLab, General Electric Healthcare, Fairfield, CT, USA).

The MLHFQ is a self-administered disease-specific questionnaire for patients with HF [8], comprising 21 items rated on 6-point Likert scales, representing different degrees of impact of HF on health-related quality of life (HRQoL), from 0 (none) to 5 (very much). It provides a total score (range $0-105$, from best to worst HRQoL), as well as 2 subscores, somatic ( 8 items, range $0-40$ ) and emotional (5 items, range 0-25), which explores the impact of physical and psychological dimensions on HRQoL.

The CP status was based on the individual answer to question 1 of MLHFQ (during the past month, has your heart problem prevented you from living as you wanted because it caused swelling in your ankles or legs?) and was defined by a score $>2$. Gravity-dependent leg edema is the most clinically recognizable surrogate of congestion [9]. Since the degree of congestion varies over time, we assumed that patient self-reported severity of congestion would capture tendency to edema formation better than 1-time congestion assessment. Clinical signs of systemic (defined by the presence of elevated jugular pressure, hepatomegaly, or ascites and leg edema) or lung congestion (defined by venostasis on lung auscultation and chest radiogram) were also evaluated by attending physicians. A congestion score was calculated as follows: 0 , no central or systemic congestion; 1 , central or systemic congestion; 2 , central and systemic congestion.

Glomerular filtration rate (GFR) was estimated using the Modification of Diet in the Renal Disease equation [10]. Plasma sodium, albumin, aspartate-aminotransferase, glucose, and creatinine were measured by using an automated Abbott Architect ci1600 analyzer. Colloid oncotic pressure was derived from the plasma concentration of globulin and albumin [11]. The B-type natriuretic peptide (BNP) concentrations were measured by using microparticle immunoassay (Architect BNP, Abbott Laboratories, Chicago, IL, USA; long-term analytical coefficient of variation [CV] 4.5\%). Adiponectin was measured using the high-sensitivity enzyme-linked immunoadsorbent assay (BioVendor, Brno, Czech Republic; CV 6.2\%) and cortisol by the radioimmunoassay (Beckman-Coulter, Prague, Czech Republic; CV 9.2\%). Concentrations of copeptin, adrenomedullin, and endothelin-1 were assessed using the Thermo Scientific BRAHMS Biomarkers Kryptor Compact analyzer. Specifically, copeptin was measured using the copeptin proAVP assay (direct measurement range $0.7-500.0 \mathrm{pmol} / \mathrm{L}$; inter-assay CVs 5.3 and $2.8 \%$ at 4.9 and 104.5 pmol/L, respectively), endothelin- 1 was measured using the CT-proET assay (direct measurement range 3.0-500.0, inter-assay CVs 3.4 and $2.8 \%$ at 69.7 and $193.1 \mathrm{pmol} / \mathrm{L}$ ), and adrenomedullin was measured using the MR-proADM assay (direct measurement range 0.05-10.00 nmol/L, inter-assay CVs 4.0 and $3.7 \%$ at 0.7 and $4.3 \mathrm{nmol} / \mathrm{L}$ ). Serum insulin was measured by immunochemiluminescence (IMMULITE 2000, Diagnostic Products, Los Angeles, CA, USA; CVs <10\%).

An adverse outcome was defined as a combined endpoint of death, urgent transplantation, or assist device implantation without heart transplantation. Since time to nonurgent transplantation reflects donor availability rather than recipient condition, such patients were censored as having no outcome at the day of transplantation.

Data were analyzed by using JMP 10 software (SAS Institute, Inc., Cary, NC, USA). A twosided $p$ value of $<0.05$ was considered statistically significant. Data are presented as means \pm SD or medians (interquartile ranges), where appropriate. Differences between groups were tested by using the chi-square test, unpaired Student $t$ test, or analysis of variance. To assess the association of each variable with CP status, separate multiple logistic regression analyses were conducted. Variables not normally distributed had been log-transformed before the analysis. Highly significant univariate variables ( $p$ value $<0.001$ ) were included in the multivariate model. Cox proportional hazard regression was used to analyze the factors associated with all-cause mortality, and hazard ratios (HR) and 95\% CIs were calculated. Kaplan-Meier curves with the log-rank statistic were used to illustrate the outcome. 


\section{Kidney \\ Blood Pressure Research}

\begin{tabular}{l|l}
\hline Kidney Blood Press Res 2019;44:1271-1284 \\
\hline DOI: 10.1159/000502975 & $\begin{array}{l}\text { @ } 2019 \text { The Author(s). Published by S. Karger AG, Basel } \\
\text { www.karger.com/kbr }\end{array}$ \\
\hline
\end{tabular}

Monzo et al:: Adiponectin in Congestive HF

Table 1. Characteristics of total cohort and classified by congestion or non-CP status

\begin{tabular}{|c|c|c|c|c|}
\hline Variables & Total $(n=371)$ & Non-CP $(n=256)$ & $\mathrm{CP}(n=115)$ & $p$ value \\
\hline \multicolumn{5}{|l|}{ Demographic data } \\
\hline Age, years & $59 \pm 11$ & $58 \pm 11$ & $59 \pm 11$ & 0.65 \\
\hline Gender, male, $n(\%)$ & $317(85)$ & $218(85)$ & $99(86)$ & 0.87 \\
\hline Ischemic etiology of $\mathrm{HF}, n(\%)$ & $196(53)$ & $138(54)$ & $58(50)$ & 0.57 \\
\hline HF duration, years & $6.3(2.3-11.7)$ & $6.3(2.4-11.6)$ & $6.6(2.1-12.6)$ & 0.92 \\
\hline Diabetes mellitus, $n(\%)$ & $123(33)$ & $75(29)$ & $48(42)$ & 0.02 \\
\hline COPD/asthma, $n(\%)$ & $55(15)$ & $36(14)$ & $19(16)$ & 0.53 \\
\hline BW loss in past 6 months ( $\%$ of BW) & $-2.66 \pm 9.81$ & $-1.27 \pm 8.73$ & $-5.72 \pm 11.29$ & $<0.001$ \\
\hline NYHA class $(1-4)$ & $2.8 \pm 0.6$ & $2.7 \pm 0.6$ & $2.9 \pm 0.5$ & 0.006 \\
\hline Systolic blood pressure, mm Hg & $114 \pm 19$ & $115 \pm 19$ & $112 \pm 18$ & 0.27 \\
\hline Heart rate, bpm & $78 \pm 15$ & $77 \pm 15$ & $79 \pm 14$ & 0.21 \\
\hline Lung congestion, $n(\%)$ & $36(10)$ & $19(7)$ & $17(15)$ & 0.04 \\
\hline Systemic congestion, $n(\%)$ & $91(24)$ & $33(13)$ & $58(50)$ & $<0.001$ \\
\hline BMI, $\mathrm{kg} / \mathrm{m}^{2}$ & $28 \pm 5$ & $28 \pm 4$ & $28 \pm 5$ & 0.11 \\
\hline Implantable cardioverter defibrillator, $n(\%)$ & $241(65)$ & $171(67)$ & $70(61)$ & 0.29 \\
\hline Cardiac resynchronization therapy, $n(\%)$ & $166(45)$ & $118(46)$ & $48(42)$ & 0.50 \\
\hline \multicolumn{5}{|l|}{ Medications } \\
\hline $\mathrm{BB}, n(\%)$ & $344(93)$ & $246(96)$ & $98(85)$ & $<0.001$ \\
\hline ACEi/ARBs, $n(\%)$ & $314(85)$ & $217(85)$ & $97(84)$ & 0.99 \\
\hline Aldosterone antagonist, $n(\%)$ & $287(77)$ & $200(78)$ & $87(76)$ & 0.59 \\
\hline Loop diuretics, $n(\%)$ & $343(92)$ & $236(92)$ & $107(93)$ & 0.83 \\
\hline Furosemide - daily dose, mg & $80(40-125)$ & $62(40-120)$ & $80(60-125)$ & $<0.001$ \\
\hline \multicolumn{5}{|l|}{ Echocardiographic data } \\
\hline LVEF, \% & $25 \pm 6$ & $25 \pm 5$ & $25 \pm 7$ & 0.50 \\
\hline LV mass index, $\mathrm{g} / \mathrm{m}^{2}$ & $141 \pm 36$ & $142 \pm 35$ & $138 \pm 37$ & 0.29 \\
\hline LV end-diastolic diameter, $\mathrm{mm}$ & $70 \pm 9$ & $71 \pm 9$ & $69 \pm 9$ & 0.05 \\
\hline Left atrium diameter, $\mathrm{mm}$ & $50 \pm 7$ & $50 \pm 6$ & $51 \pm 7$ & 0.17 \\
\hline IVC, $\mathrm{mm}$ & $20 \pm 6$ & $19 \pm 6$ & $23 \pm 7$ & $<0.001$ \\
\hline RVD, $n(\%)$ & $196(53)$ & $118(46)$ & $78(68)$ & $<0.001$ \\
\hline Tricuspid regurgitation gradient, $\mathrm{mm} \mathrm{Hg}$ & $36 \pm 12$ & $37 \pm 12$ & $35 \pm 11$ & 0.06 \\
\hline RV systolic pressure, $\mathrm{mm} \mathrm{Hg}$ & $46 \pm 12$ & $47 \pm 12$ & $45 \pm 12$ & 0.50 \\
\hline Mitral regurgitation grade $(0-2)$ & & & & 0.12 \\
\hline None/mild & $140(38)$ & $103(40)$ & $37(33)$ & \\
\hline Moderate/severe & $228(62)$ & $152(60)$ & $76(67)$ & \\
\hline Tricuspid regurgitation grade $(0-2)$ & & & & $<0.001$ \\
\hline None/mild & $234(64)$ & $177(70)$ & $57(50)$ & \\
\hline Moderate/severe & $133(36)$ & $76(30)$ & $57(50)$ & \\
\hline \multicolumn{5}{|l|}{ Blood biochemistry } \\
\hline Hemoglobin, g/dL & $14.0 \pm 1.7$ & $14.1 \pm 1.5$ & $13.8 \pm 1.9$ & 0.20 \\
\hline Creatinine, $\mu \mathrm{mol} / \mathrm{L}$ & $102(86-121)$ & $100(85-121)$ & $104(88-127)$ & 0.23 \\
\hline Urea, mmol/L & $8.3(6.3-11.0)$ & $7.8(6.0-10.0)$ & $9.8(6.9-12.7)$ & 0.001 \\
\hline $\mathrm{GFR}, \mathrm{mL} / \mathrm{min} / 1.73 \mathrm{~m}^{2}$ & $69 \pm 23$ & $70 \pm 24$ & $67 \pm 21$ & 0.13 \\
\hline Albumin, g/L & $38 \pm 4$ & $39 \pm 4$ & $37 \pm 4$ & $<0.001$ \\
\hline Sodium, mmol/L & $140 \pm 4$ & $140 \pm 3$ & $139 \pm 4$ & 0.004 \\
\hline Potassium, mmol/L & $4.4 \pm 0.4$ & $4.3 \pm 0.4$ & $4.4 \pm 0.5$ & 0.69 \\
\hline C-reactive protein, $\mathrm{mg} / \mathrm{L}$ & $4.2(1.1-9.1)$ & $3.4(0.9-8.1)$ & $5.7(2.2-12.7)$ & 0.02 \\
\hline Hemoglobin A1C, \% & $4.5(4.0-5.1)$ & $4.4(4.0-5.0)$ & $4.7(4.2-5.7)$ & 0.005 \\
\hline Glucose, $\mathrm{mmol} / \mathrm{L}$ & $6.3 \pm 2.4$ & $6.0 \pm 1.7$ & $6.7 \pm 3.6$ & 0.06 \\
\hline Colloid-oncotic pressure, $\mathrm{mm} \mathrm{Hg}$ & $31 \pm 3$ & $31 \pm 3$ & $30 \pm 3$ & 0.009 \\
\hline
\end{tabular}

Data are mean and SD if the variable is normally distributed and median and IQR if not. The statistical difference between variables is given for the comparison between patients with congestion and non-CP status.

$\mathrm{CP}$, congestion-prone; ARB, angiotensin receptor blocker; COPD, chronic obstructive pulmonary disease; MLHFQ, Minnesota Living with Heart Failure Questionnaire; NYHA, New York Heart Association; HF, heart failure; BW, body weight; LV, left ventricle; LVEF, LV ejection fraction; IVC, inferior vena cava; RVD, right ventricular dysfunction; RV, right ventricular; GFR, glomerular filtration rate; IQR, interquartile range; BMI, body mass index; BB, beta-blockers. 


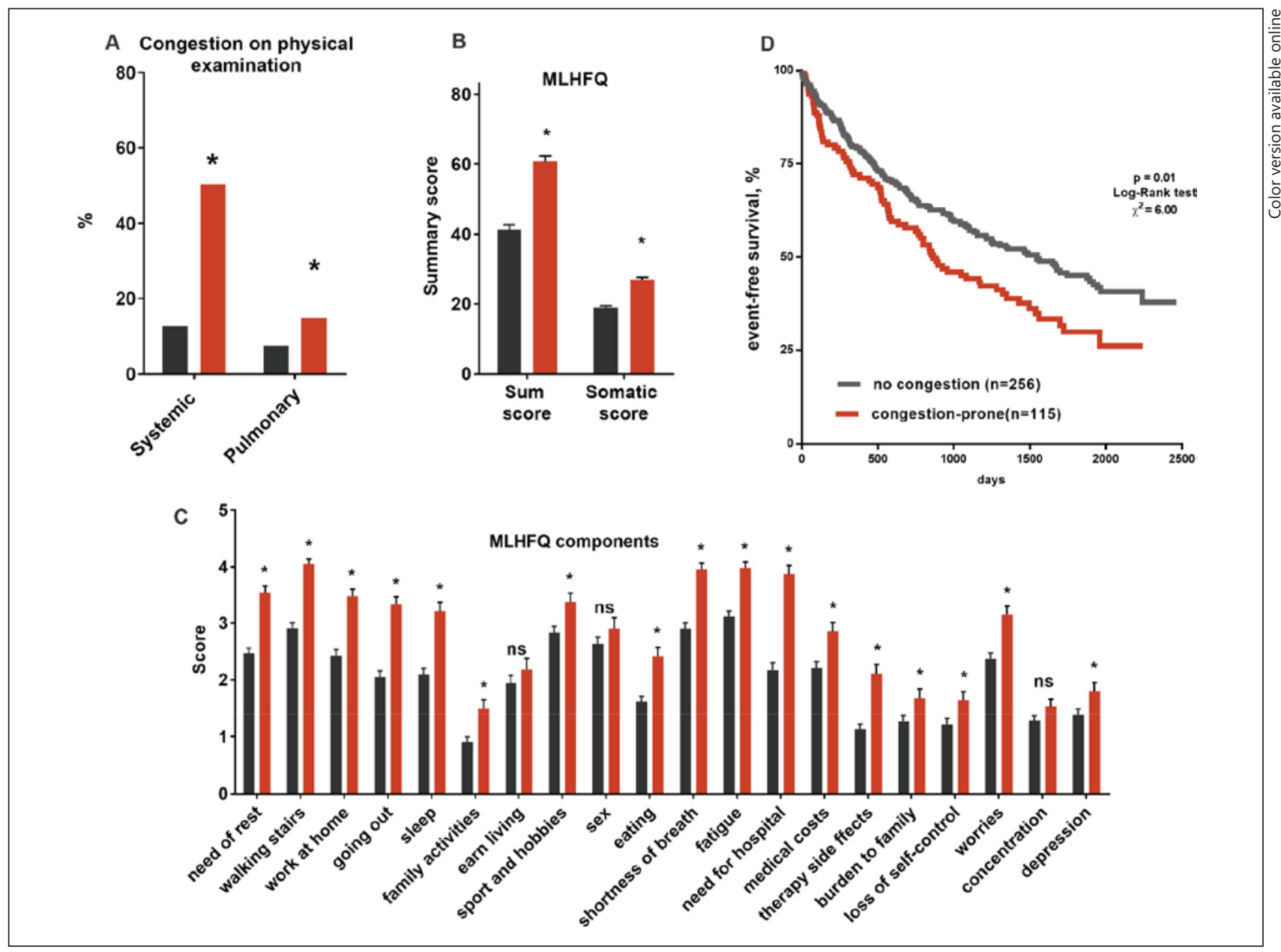

Fig. 1. Differences in physical examination, MLHFQ and survival between CP and non-CP patients. A Objective evidence of systemic and pulmonary congestion. B MLHFQ total score and somatic score. C MLHFQ single queries. D Kaplan-Meier plot displaying the effect of having or not a CP status on freedom from adverse events (combined endpoint of death, urgent transplantation, or assist device implantation without heart transplantation). MLHFQ, Minnesota Living with HF questionnaire; ns, not significant.

\section{Results}

\section{Patients Characteristics}

A total of 371 subjects with chronic HF were enrolled in the study. The population was well medically treated with $93 \%$ of patients on beta-blockers (BB) and $85 \%$ of patients on angiotensin converting enzyme inhibitors (ACEi) with high prevalence of cardiac resynchronization therapy or ICDs (Table 1). On echocardiography, patients showed severe reduction of LV function (LVEF $25 \pm 6 \%$ ), and moderate to severe RV dysfunction was found in $53 \%$. IVC dilation ( $>20 \mathrm{~mm}$ ) was present in $44 \%$ of cases and pulmonary hypertension with an estimated RV systolic pressure $>35 \mathrm{~mm} \mathrm{Hg}$ in $80 \%$ (Table 1).

\section{The Influence of the CP Status on Quality of Life and Prognosis}

The CP status was present in $31 \%$ of patients $(n=115)$ in our cohort. CP patients frequently had objective evidence of systemic venous congestion (50\%), but less often that of pulmonary congestion (14\%; Fig. 1A). The presence of CP had a profound effect on quality 


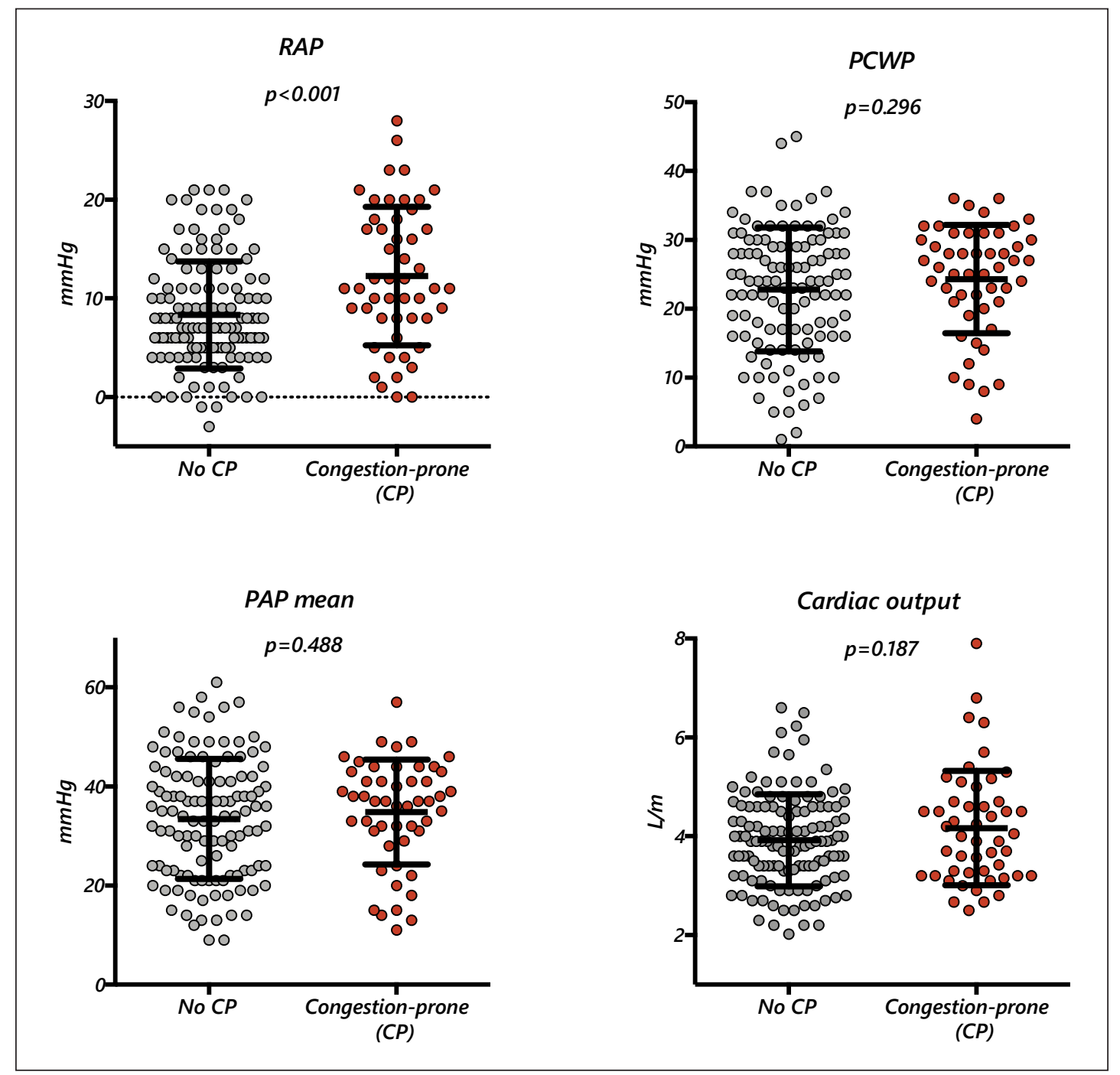

Fig. 2. Results of right heart catheterization divided by $\mathrm{CP}$ and non-CP patients. Lines and brackets represent mean \pm SD. PAP, pulmonary artery pressure; PCWP, pulmonary capillary wedge pressure; RAP, right atrial pressure; $\mathrm{CP}$, congestion-prone.

of life (Fig. 1C). Both MLHFQ sum score (Fig. 1B) and New York Heart Association functional class (Table 1) were significantly elevated in CP patients. During a median follow-up of 1,093 (interquartile range 337-1,697) days, 159 (43\%) of 371 patients had an adverse event. CP status was strongly associated with poor outcome (HR 1.43; 95\% CI 1.07-1.90; $p=0.01$; Fig. 1D).

\section{CP Status: Measurements and Correlates}

CP patients showed higher daily dose of furosemide than non-CP patients. They also had lower prescription rate of $\mathrm{BB}$, but no differences were found in mineralocorticoid antagonists or ACEi/angiotensin receptor blockers. The prevalence of dual or triple neurohumoral inhibitors (BB, ACEi/angiotensin receptor blockers and mineralocorticoid antagonists) was equal in $\mathrm{CP}$ and non-CP group. $\mathrm{CP}$ group had higher prevalence of diabetes and higher percentage of BW loss in the last 6 months, but similar body mass index. The degree of congestion correlated with BW loss $\left(R^{2}=0.05, p<0.001\right)$, pointing out the concept that congestion was more 


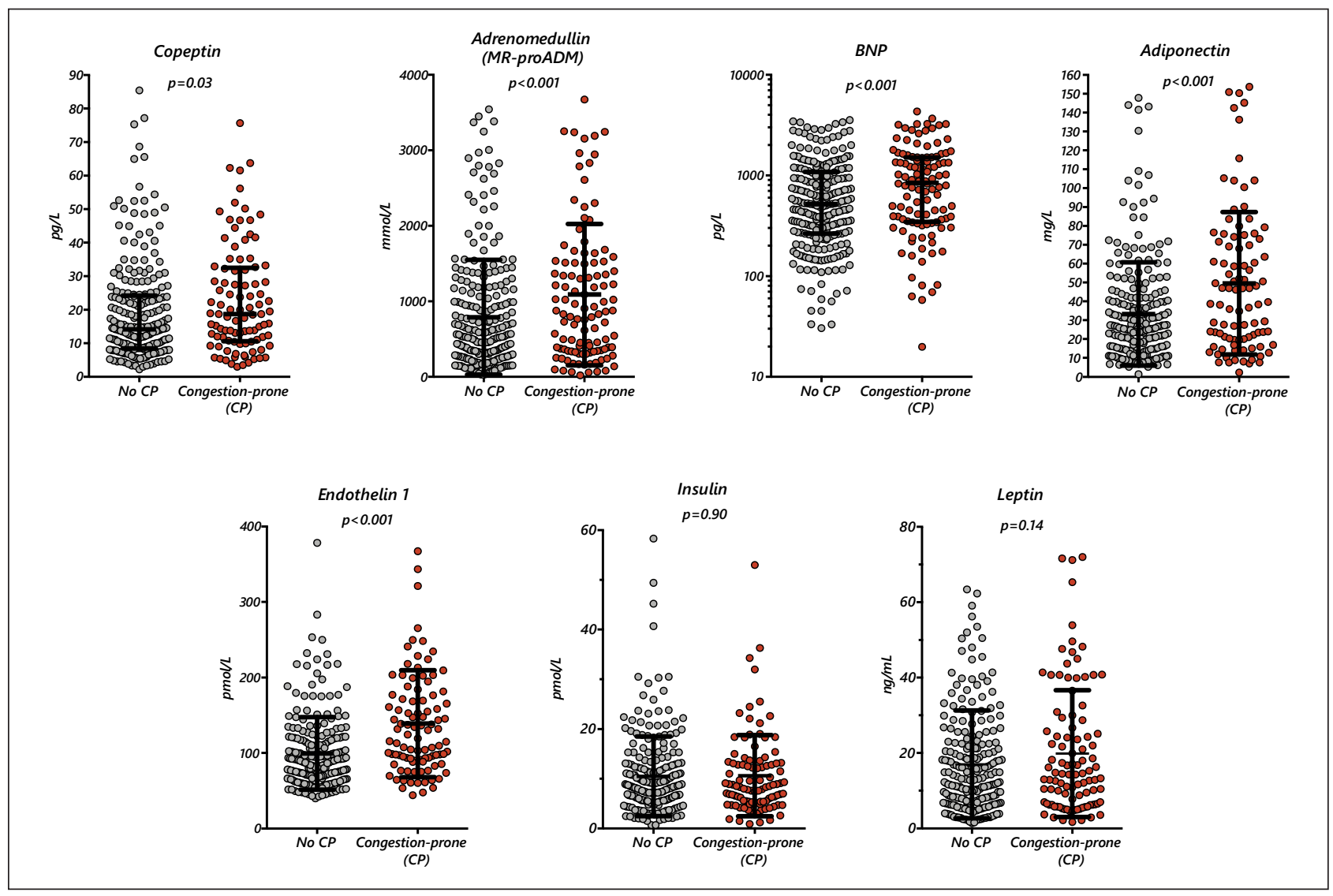

Fig. 3. Hormones evaluation in HF. Plasma hormones distribution in $\mathrm{CP}$ and non-CP patients. Lines and brackets represent mean \pm SD (for BNP and Copeptin median and IQR). BNP, B-type natriuretic peptide; CP, congestion-prone.

common in patients with cardiac cachexia. CP patients had higher plasma concentrations of inflammation proteins and urea and lower of electrolytes and albumin. Consequently, the colloid-oncotic pressure was significantly reduced in CP patients (Table 1).

$\mathrm{CP}$ subjects had more significant (moderate to severe) tricuspid valve regurgitation, larger IVC dimensions, and more impaired RV function compared with those without the CP status (Table 1). Among all invasive hemodynamic measures, only RAP was significantly increased in the CP group (Fig. 2).

Among CP subjects, we found elevated plasma levels in majority of tested hormones (Fig. 3). In contrast, HF etiology and duration, LVEF, hemoglobin, and GFR were similar in the 2 groups. Univariate and multivariate logistic regressions were used to delineate which cardiac, clinical, and humoral factors were independently associated with CP status (Table 2).

In the univariate analysis, increased levels of hormones (with the exception of cortisol) and urea, dilated IVC, worse RV function and tricuspid regurgitation, higher RAP and daily dose of furosemide, and a reduced prescription of $\mathrm{BB}$ were directly correlated with the $\mathrm{CP}$ status. In contrast, weight loss and lower albumin were inversely correlated.

In the multivariate regression, RV dysfunction and IVC remained the only echocardiographic-independent predictors of the CP status. Similarly, albumin, and among humoral variables adiponectin, maintained a strong independent relationship to congestion development (Fig. 4). No clinical parameters were associated with the CP status in the multivariate analysis. 
Table 2. Variables associated with CP status in patients with HF by univariable and multivariable logistic regression model

\begin{tabular}{|c|c|c|c|c|}
\hline Variable & $\begin{array}{l}\text { Regression } \\
\text { Coefficient }\end{array}$ & $p$ value & $\begin{array}{l}\text { Unstandardized } \\
\text { Coefficients }(95 \% \mathrm{CI})\end{array}$ & $\begin{array}{l}t \text { stat } \\
(p \text { value })\end{array}$ \\
\hline \multicolumn{5}{|l|}{ Demographics } \\
\hline Age, years & 0.048 & 0.357 & & \\
\hline Systolic blood pressure, $\mathrm{mm} \mathrm{Hg}$ & -0.092 & 0.075 & & \\
\hline Heart rate, bpm & 0.041 & 0.421 & & \\
\hline BMI, $\mathrm{kg} / \mathrm{m}^{2}$ & 0.066 & 0.210 & & \\
\hline HF duration, years & 0.028 & 0.620 & & \\
\hline Ischemic etiology of HF (yes vs. no) & 0.015 & 0.763 & & \\
\hline NYHA class $(1-4)$ & 0.143 & 0.006 & & \\
\hline $\mathrm{BW}, \mathrm{kg}$ & 0.054 & 0.297 & & \\
\hline BW loss in past 6 months ( $\%$ of BW) & -0.226 & $<0.001$ & $-0.009(-0.030$ to 0.010$)$ & ns \\
\hline Diabetes mellitus (no vs. yes) & 0.159 & 0.022 & J ( & HO \\
\hline \multicolumn{5}{|l|}{ Blood biochemistry } \\
\hline $\mathrm{GFR}, \mathrm{mL} / \mathrm{min} / 1.73 \mathrm{~m}^{2}$ & -0.065 & 0.209 & & \\
\hline Urea, mmol/L & 0.203 & $<0.001$ & $0.009(-0.048$ to 0.067$)$ & ns \\
\hline Hemoglobin, g/dL & -0.091 & 0.091 & & \\
\hline Albumin, $\mathrm{g} / \mathrm{L}$ & -0.178 & $<0.001$ & $-0.084(-0.134$ to -0.033$)$ & 0.001 \\
\hline Hemoglobin A1C, \% & 0.199 & 0.001 & & \\
\hline Sodium, mmol/L & -0.153 & 0.003 & & \\
\hline Potassium, mmol/L & 0.043 & 0.411 & & \\
\hline \multicolumn{5}{|l|}{ Hormones } \\
\hline $\log [\mathrm{BNP}]$ & 0.178 & $<0.001$ & $-0.125(-0.384$ to 0.133$)$ & ns \\
\hline Adiponectin, mg/L & 0.247 & $<0.001$ & $0.008(0.001$ to 0.014$)$ & 0.016 \\
\hline Cortisol, nmol/L & 0.062 & 0.254 & & \\
\hline MR-proAM, nmol/L & 0.347 & $<0.001$ & $0.487(-0.214$ to 1.190$)$ & ns \\
\hline $\log [$ Copeptin] & 0.128 & 0.019 & & \\
\hline Endothelin-1, pmol/L & 0.329 & $<0.001$ & $0.001(-0.006$ to 0.009$)$ & ns \\
\hline Log [Insulin] & 0.047 & 0.707 & & \\
\hline Log [Leptin] & 0.054 & 0.321 & & \\
\hline \multicolumn{5}{|l|}{ Echocardiography } \\
\hline $\mathrm{LV}$ end-diastolic diameter, $\mathrm{mm}$ & -0.092 & 0.076 & & \\
\hline LVEF, $\%$ & 0.012 & 0.812 & & \\
\hline Tricuspid regurgitation grade $(0-2)$ & 0.237 & $<0.001$ & $-0.027(-0.346$ to 0.291$)$ & ns \\
\hline IVC diameter, $\mathrm{mm}$ & 0.298 & $<0.001$ & $0.048(0.008$ to 0.088$)$ & 0.017 \\
\hline Left atrium diameter, $\mathrm{mm}$ & 0.092 & 0.075 & & \\
\hline $\mathrm{LV}$ mass index, $\mathrm{g} / \mathrm{m}^{2}$ & -0.054 & 0.302 & & \\
\hline RVD $(0-3)$ & 0.224 & $<0.001$ & $0.262(0.028$ to 0.497$)$ & 0.028 \\
\hline \multicolumn{5}{|l|}{ Hemodynamic $\#$} \\
\hline RAP, mm Hg & 0.276 & $<0.001$ & & \\
\hline Pulmonary artery mean pressure, $\mathrm{mm} \mathrm{Hg}$ & 0.049 & 0.511 & & \\
\hline Pulmonary capillary wedge pressure, $\mathrm{mm} \mathrm{Hg}$ & 0.056 & 0.453 & & \\
\hline Cardiac output, L/min & 0.038 & 0.613 & & \\
\hline \multicolumn{5}{|l|}{ Medications } \\
\hline Furosemide dose, mg/day & 0.212 & $<0.001$ & $0.002(-0.001$ to -0.004$)$ & ns \\
\hline Furosemide (no vs. yes) & 0.029 & 0.571 & & \\
\hline BB (no vs. yes) & 0.150 & $<0.001$ & $0.277(-0.159$ to -0.715$)$ & ns \\
\hline ACEi/ARBs (no vs. yes) & 0.044 & 0.399 & & \\
\hline
\end{tabular}

Variables entered in MV analysis: Tricuspid Regurgitation; IVC Diameter; RVD; Adrenomedullin; BNP; Endothelin; Adiponectin; Urea; Beta-Blockers (no vs yes); Furosemide Daily Dose; BW loss; Albumin.

${ }^{\#}$ Hemodynamic parameters available from 175 subjects.

$\mathrm{CP}$, congestion prone; $\mathrm{HF}$, heart failure; $\mathrm{ACEi}$, angiotensin converting enzyme inhibitors; $\mathrm{ARBs}$, angiotensin receptor blockers; BNP, B-type natriuretic peptide; BW, body weight; MR-proAM, mid-regional pro-adrenomedullin; NYHA, New York Heart Association; BW, body weight; GFR, glomerular filtration rate; LVEF, left ventricle ejection fraction; IVC, inferior vena cava; LV, left ventricular; RV, right ventricular dysfunction; RAP, right atrial pressure; BMI, body mass index; BB, beta-blockers; ns, not significant. 


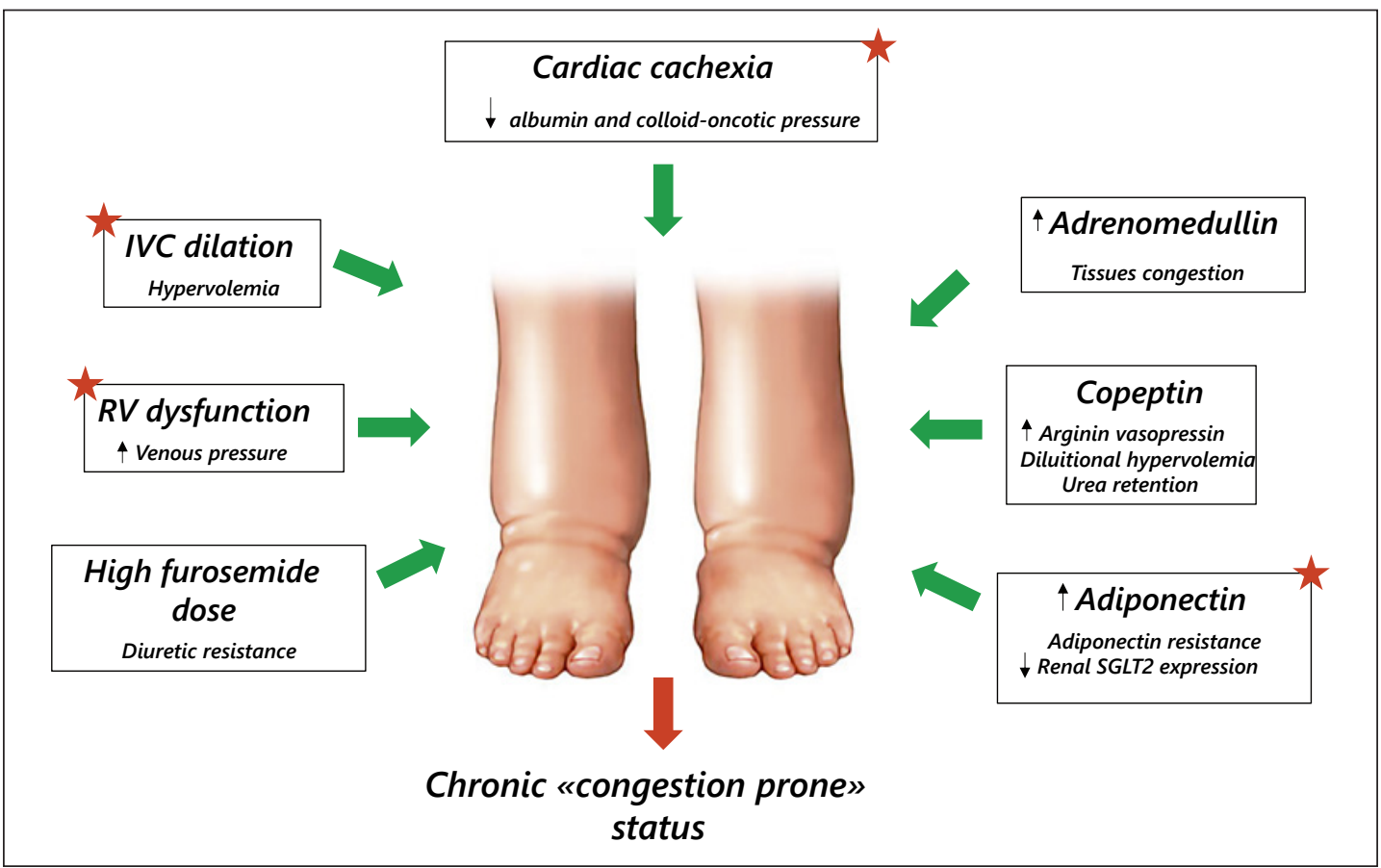

Fig. 4. Determinants of CP status. Independent predictors are indicated by red stars. IVC, inferior vena cava; $\mathrm{RV}$, right ventricular.

Table 3. Variables associated with adiponectin in patients with HF

\begin{tabular}{llr}
\hline Variable & $\begin{array}{l}\text { Univariable analysis } \\
\text { Regression coefficient }\end{array}$ & $p$ value \\
\hline BMI, kg/m² & -0.323 & $<0.001$ \\
BW loss in past 6 months (\% of BW) & -0.291 & $<0.001$ \\
Diabetes mellitus & -0.087 & 0.120 \\
Log (BNP) & 0.416 & $<0.001$ \\
Congestion score (0-2) & 0.123 & 0.028 \\
Log (fasting insulin) & -0.261 & $<0.001$ \\
LVEF, \% & -0.069 & 0.213 \\
GFR, mL/min/1.73 m $^{2}$ & -0.024 & 0.665 \\
\hline
\end{tabular}

Congestion score was calculated as follows: 0 , no central or systemic congestion; 1 , central or systemic congestion; 2, central and systemic congestion.

HF, heart failure; BW, body weight; BNP, B-type Natriuretic peptide; BW, body weight; LVEF, left ventricular ejection fraction; GFR, glomerular filtration rate; BMI, body mass index.

Adiponectin concentration showed a significant increase in patients with clinical evidence of systemic congestion, but not in those with pulmonary congestion (online suppl. Fig. S1; for all online suppl. material, see www.karger.com/doi/10.1159/000502975). It was also strongly correlated $(p<0.001)$ with BNP, body mass index, weight loss, and insulin concentration but not with renal function and diabetic status (Table 3). In the MLHFQ, adiponectin showed the strongest association with the question 1 (edema, $p<0.001$ ), the question 11 (anorexia, $p<0.001$ ), and the question 14 (hospitalization, $p=0.02$ ). Adiponectin by itself was 


\section{Kidney \\ Blood Pressure \\ Research}

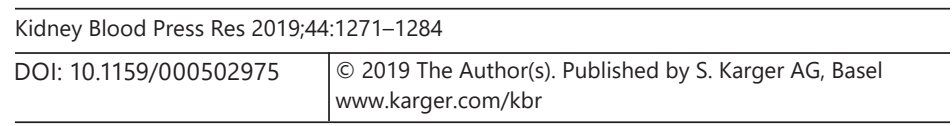

Monzo et al.: Adiponectin in Congestive HF

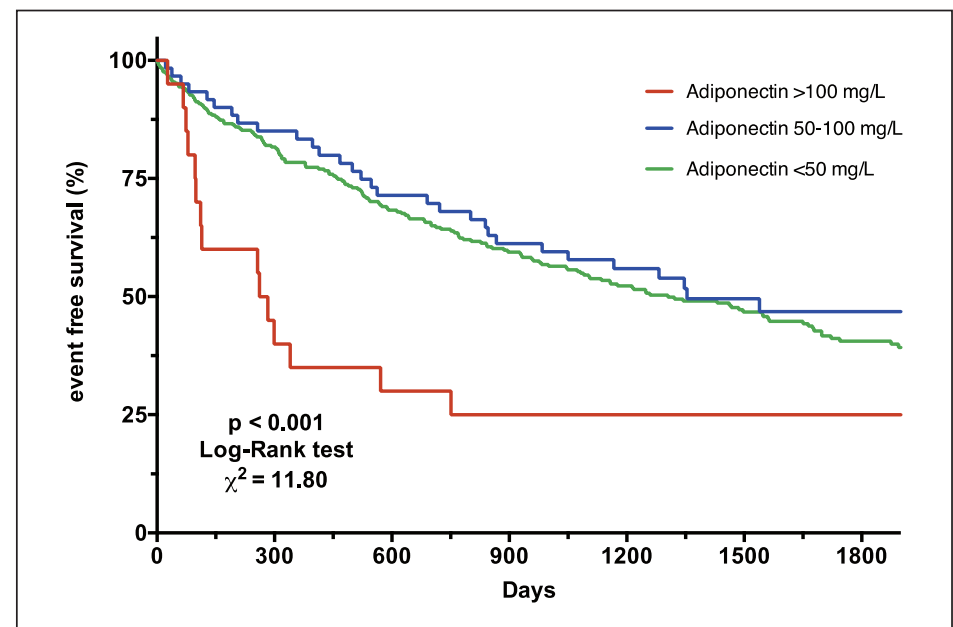

Fig. 5. Kaplan-Meier plot displaying the effect of different concentrations of adiponectin on freedom from adverse events (combined endpoint of death, urgent transplantation, or assist device implantation without heart transplantation).

predictive of adverse events (Fig. 5), with the higher concentration tertile ( $>100 \mathrm{mg} / \mathrm{L}$ ) that evidenced an increase in the risk of primary outcome more than two-fold compared to the lower tertiles (HR 2.55, 95\% CI [1.43-4.20], $p=0.002$ ). Finally, if CP status was entered in a multivariate model with adiponectin, it was no longer predictive of adverse events, but adiponectin was still significant, suggesting as part of the association between congestion and outcome may be mediated by this hormone.

\section{Discussion}

The main finding of the study is that HF patients more prone to systemic congestion are characterized not only by higher neurohormonal activation, hypoproteinaemia, and RV dysfunction but also by increased levels of fat-derived hormone adiponectin. Adiponectin remained independently associated with congestion in multivariate analysis and mediated the impact of congestion on prognosis, indicating potentially relevant role in fluid retention. In contrast, factors traditionally considered as determinants of edema, such as decreased renal function, low cardiac output, or increased natriuretic peptides, were reported to be less relevant for CP status in our cohort. Our study indicates that in addition to adequate use of diuretics, the strategies to improve control of chronic congestion should target RV function and additional hormonal systems besides sympathetic or renin-angiotensin system.

Adiponectin is an adipocyte-derived cytokine with cardioprotective effects mediated by antiapoptotic, fibrosis-reducing, and oxidative stress diminishing properties [12]. It regulates cellular function via the binding of its receptors adiponectin receptor 1 and adiponectin receptor 2 that are variously expressed in adult cardiomyocytes, skeletal muscle, endothelial cells, liver, and kidneys [13]. In healthy individuals and in coronary artery disease, low plasma adiponectin levels have been associated with insulin resistance and excess of cardiovascular events $[14,15]$. However, in patients with established HF, high adiponectin levels are associated with worse cardiac function, more symptoms [16,17], and higher mortality, regardless of HF etiology $[18,19]$. The elevation of adiponectin concentrations in HF may be due to an increased stimulation, due to blunted hormone signaling, or a combination of both mechanisms. In this regard, clinical and experimental studies demonstrated the downregulation and desensitization of adiponectin receptors in the heart and skeletal muscle of HF patients, suggesting a reduced biologic response to adiponectin due to hormonal resistance [20-22]. On the other hand, the stimulation of adiponectin secretion by natriuretic peptides was previ- 
ously reported [23]. The reasons for the paradoxical adverse prognosis associated with elevated adiponectin plasma concentrations in HF are incompletely understood. Increased adiponectin levels may promote congestion by an increase of adrenal aldosterone secretion [24]. Interestingly, adiponectin can also affect glucose transporters in the kidney. In a recent experimental study [25], this hormone was shown to regulate renal sodium/glucose cotransporter 2, which in turn affects reabsorption of sodium and glucose and may contribute to a homeostatic attempt to decrease the vicious circle of congestion. This rescue mechanism may be ineffective because of the impaired adiponectin signaling in HF patients. In summary, our data suggest that the influence of adiponectin on prognosis in $\mathrm{HF}$ can be mediated by promoting congestion. Whether interventions on adiponectin signaling pathways using therapeutic agents able to prevent downregulation or desensitization of adiponectin receptors could affect preponderance to congestion should be further experimentally investigated.

In this report, we confirmed only weak correlation between invasive hemodynamic data and congestion $[26,27]$. RAP, but not cardiac output or pulmonary wedge pressure, was associated with the CP status. Similarly, correlation between intravascular volume (expressed by RAP and its surrogate IVC diameter) and volume overload in HF is poor [27], as other important factors such as venous capacitance [28] and partitioning of retained water between intravascular and extravascular space [29] play important roles.

RV dysfunction was highly prevalent in the CP group and strongly correlated with congested status, confirming its critical pathophysiologic role in HF patients [6]. Strategies to improve RV function will be crucial to prevent development of CP state and to protect organs from untoward effects of chronic venous hypertension [30].

In agreement with previous studies [31,32], our report confirmed a strong correlation between congestion and hypoalbuminemia (and reduced colloid-oncotic pressure). Impaired liver [29] or renal function [32], hemodilution, and an increased inflammatory activity [31, 33] are likely contributing to reduced albumin concentration in HF patients.

Blood urea concentration, but not GFR, correlated with the CP status. Urea concentration more closely reflects neurohumoral activation in HF than in GFR [34], and particularly activation of arginine-vasopressin (AVP) system directly regulates the urea reabsorption in the collecting duct that acts on urea transporters [35]. This explains why urea blood level showed a significant increase in CP patients and it strongly correlated to stable AVP product copeptin in our study $(r=0.67)$. We found no correlation between copeptin and plasma osmolality, indicating that the main mechanism of AVP secretion is the nonosmotic release. Copeptin and Endothelin-1 elevation in CP patients corresponds to well-known causal role of these systems in free-water retention and congestion [36], although their association with CP status was less strong that with adiponectin.

The complex hormonal interactions that influence $\mathrm{CP}$ status raise questions about current approach to congestion. Besides diuretics and improving RV function, targeting additional congestion pathways (such as AVP or adiponectin) in association to the current HF therapy might provide better congestion control, which may lower hospitalization and mortality. The study also indicates that careful identification of HF patients more prone to develop congestion should lead physicians to correctly assess the risk of decompensation and then target more aggressive treatments. Recognition of the CP status should stimulate to develop and test new drugs able to interfere with development of congestion.

\section{Study Limitations}

This prospective study was observational; therefore, causality cannot be addressed. Survival analysis was performed without any adjustment for confounding factors, and this may have influenced final results. Congestion is difficult to assess, especially when symptoms are mild, and different clinical parameters are usually considered in daily clinical practice to 
detect fluid overload [37]. In our study, we only use a self-administered questionnaire to capture the tendency to edema formation, and this can lead to an erroneous estimate of the real congestion status. Due to potential referral bias, our cohort may not reflect the general HF population. Invasive hemodynamic data were available only in a subset of the study cohort. Highly optimized and managed treatment of our cohort may have influenced by some degree circulating levels of analyzed hormones and right heart catheterization results. This should be considered a strength rather than a weakness, because it allows us to consider the additional parameters beyond the contemporary standard HF treatment.

\section{Conclusions}

Some HF patients, characterized by high neurohumoral activation and RV dysfunction, are more prone to develop congestion than other. This CP status was associated in our study with more severe symptoms and higher risk of adverse outcomes. Adiponectin seems to play a role in water homeostasis and congestion development in HF patients, beyond traditional neurohumoral pathways involved in HF pathophysiology. Its use as biomarker of more severe congestion tendency and its potential role in decongestion therapy should be further examined.

\section{Disclosure Statement}

All other authors have reported that they have no conflict of interests relevant to the contents of this paper to disclose.

\section{Funding Sources}

This study was supported by Ministry of Health of the Czech Republic, grant AZV 17-28784A. The scholarship of Dr. Luca Monzo at Institute for Clinical and Experimental Medicine was supported by the "Italian Society of Cardiology."

\section{Author Contributions}

Dr. Vojtech Melenovsky and Dr. Luca Monzo conceived and designed the paper. Dr. Martin Kotrc, Dr. Ivana Jurcova and Dr. Jan Benes performed the data collection. Dr. Janka Franekova and Dr. Petr Jarolim performed the laboratory analysis. Dr. Luca Monzo, Dr. Kamil Sedlacek, Dr. Josef Kautzner and Dr. Vojtech Melenovsky performed the analysis and interpretation of data and participated in the preparation of the manuscript. All the authors read and approved the paper.

\section{References}

1 Gheorghiade M, Gattis WA, O'Connor CM, Adams KF Jr, Elkayam U, Barbagelata A, et al.; Acute and Chronic Therapeutic Impact of a Vasopressin Antagonist in Congestive Heart Failure (ACTIV in CHF) Investigators. Effects of tolvaptan, a vasopressin antagonist, in patients hospitalized with worsening heart failure: a randomized controlled trial. JAMA. 2004 Apr;291(16):1963-71.

2 Abraham WT, Adamson PB, Bourge RC, Aaron MF, Costanzo MR, Stevenson LW, et al.; CHAMPION Trial Study Group. Wireless pulmonary artery haemodynamic monitoring in chronic heart failure: a randomised controlled trial. Lancet. 2011 Feb;377(9766):658-66. 


\begin{tabular}{l|l}
\hline \multicolumn{2}{l}{ Kidney Blood Press Res 2019;44:1271-1284 } \\
\hline DOI: 10.1159/000502975 & $\begin{array}{l}\text { @ 2019 The Author(s). Published by S. Karger AG, Basel } \\
\text { www.karger.com/kbr }\end{array}$ \\
\hline
\end{tabular}

Monzo et al.: Adiponectin in Congestive HF

3 Breidthardt T, Irfan A, Klima T, Drexler B, Balmelli C, Arenja N, et al. Pathophysiology of lower extremity edema in acute heart failure revisited. Am J Med. 2012 Nov;125(11):1124.e1-8.

4 Anand IS, Ferrari R, Kalra GS, Wahi PL, Poole-Wilson PA, Harris PC. Edema of cardiac origin. Studies of body water and sodium, renal function, hemodynamic indexes, and plasma hormones in untreated congestive cardiac failure. Circulation. 1989 Aug;80(2):299-305.

5 Lang RM, Bierig M, Devereux RB, Flachskampf FA, Foster E, Pellikka PA, et al.; American Society of Echocardiography's Nomenclature and Standards Committee; Task Force on Chamber Quantification; American College of Cardiology Echocardiography Committee; American Heart Association; European Association of Echocardiography, European Society of Cardiology. Recommendations for chamber quantification. Eur J Echocardiogr. 2006 Mar;7(2):79-108.

6 Melenovsky V, Kotrc M, Borlaug BA, Marek T, Kovar J, Malek I, et al. Relationships between right ventricular function, body composition, and prognosis in advanced heart failure. J Am Coll Cardiol. 2013 Oct;62(18): 1660-70.

7 Anker SD, Ponikowski P, Varney S, Chua TP, Clark AL, Webb-Peploe KM, et al. Wasting as independent risk factor for mortality in chronic heart failure. Lancet. 1997 Apr;349(9058):1050-3.

8 Rector TS, Kubo SH, Cohn JN. Patients' self-assessment of their congestive heart failure. Part 2: content, reliability and validity of a new measure, The Minnesota Living with Heart Failure Questionnaire. Heart Fail. 1987;3:198-209.

9 Damy T, Kallvikbacka-Bennett A, Zhang J, Goode K, Buga L, Hobkirk J, et al. Does the physical examination still have a role in patients with suspected heart failure? Eur J Heart Fail. 2011 Dec;13(12):1340-8.

10 Levey AS, Bosch JP, Lewis JB, Greene T, Rogers N, Roth D; Modification of Diet in Renal Disease Study Group. A more accurate method to estimate glomerular filtration rate from serum creatinine: a new prediction equation. Ann Intern Med. 1999 Mar;130(6):461-70.

11 Marini JJ WA: Critical Care Medicine: The Essentials. 2012.

12 Kadowaki T, Yamauchi T. Adiponectin and adiponectin receptors. Endocr Rev. 2005 May;26(3):439-51.

13 Yan J, Yang H, Gan L, Sun C. Adiponectin-impaired adipocyte differentiation negatively regulates fat deposition in chicken. J Anim Physiol Anim Nutr (Berl). 2014 Jun;98(3):530-7.

14 Kumada M, Kihara S, Sumitsuji S, Kawamoto T, Matsumoto S, Ouchi N, et al.; Osaka CAD Study Group. Coronary artery disease. Association of hypoadiponectinemia with coronary artery disease in men. Arterioscler Thromb Vasc Biol. 2003 Jan;23(1):85-9.

15 Pischon T, Girman CJ, Hotamisligil GS, Rifai N, Hu FB, Rimm EB. Plasma adiponectin levels and risk of myocardial infarction in men. JAMA. 2004 Apr;291(14):1730-7.

16 Kistorp C, Faber J, Galatius S, Gustafsson F, Frystyk J, Flyvbjerg A, et al. Plasma adiponectin, body mass index, and mortality in patients with chronic heart failure. Circulation. 2005 Sep;112(12):1756-62.

17 Laoutaris ID, Vasiliadis IK, Dritsas A, Mavrogeni S, Kallistratos MS, Manginas A, et al. High plasma adiponectin is related to low functional capacity in patients with chronic heart failure. Int J Cardiol. 2010 Oct;144(2): $230-1$

18 Tamura T, Furukawa Y, Taniguchi R, Sato Y, Ono K, Horiuchi H, et al. Serum adiponectin level as an independent predictor of mortality in patients with congestive heart failure. Circ J. 2007 May; 71(5):623-30.

19 Baltrūnienė V, Bironaitė D, Kažukauskienė I, Bogomolovas J, Vitkus D, Ručinskas K, et al. The Role of Serum Adiponectin for Outcome Prediction in Patients with Dilated Cardiomyopathy and Advanced Heart Failure. BioMed Res Int. 2017;2017:3818292.

20 Van Berendoncks AM, Garnier A, Beckers P, Hoymans VY, Possemiers N, Fortin D, et al. Functional adiponectin resistance at the level of the skeletal muscle in mild to moderate chronic heart failure. Circ Heart Fail. 2010 Mar;3(2):185-94.

21 Wang Y, Gao E, Lau WB, Wang Y, Liu G, Li JJ, et al. G-protein-coupled receptor kinase 2-mediated desensitization of adiponectin receptor 1 in failing heart. Circulation. 2015 Apr;131(16):1392-404.

22 Wang Y, Ma XL, Lau WB. Cardiovascular Adiponectin Resistance: The Critical Role of Adiponectin Receptor Modification. Trends Endocrinol Metab. 2017 Jul;28(7):519-30.

23 Yamauchi T, Kamon J, Minokoshi Y, Ito Y, Waki H, Uchida S, et al. Adiponectin stimulates glucose utilization and fatty-acid oxidation by activating AMP-activated protein kinase. Nat Med. 2002 Nov;8(11):1288-95.

24 Kamari Y, Shimoni N, Koren F, Peleg E, Sharabi Y, Grossman E. High-salt diet increases plasma adiponectin levels independent of blood pressure in hypertensive rats: the role of the renin-angiotensin-aldosterone system. J Hypertens. 2010 Jan;28(1):95-101.

25 Zhao Y, Gao P, Sun F, Li Q, Chen J, Yu H, et al. Sodium Intake Regulates Glucose Homeostasis through the PPARס/Adiponectin-Mediated SGLT2 Pathway. Cell Metab. 2016 Apr;23(4):699-711.

26 Adamson PB, Gold MR, Bennett T, Bourge RC, Stevenson LW, Trupp R, et al. Continuous hemodynamic monitoring in patients with mild to moderate heart failure: results of The Reducing Decompensation Events Utilizing Intracardiac Pressures in Patients With Chronic Heart Failure (REDUCEhf) trial. Congest Heart Fail. 2011 Sep-Oct;17(5):248-54.

27 Bourge RC, Abraham WT, Adamson PB, Aaron MF, Aranda JM Jr, Magalski A, et al.; COMPASS-HF Study Group. Randomized controlled trial of an implantable continuous hemodynamic monitor in patients with advanced heart failure: the COMPASS-HF study. J Am Coll Cardiol. 2008 Mar;51(11):1073-9.

28 Fallick C, Sobotka PA, Dunlap ME. Sympathetically mediated changes in capacitance: redistribution of the venous reservoir as a cause of decompensation. Circ Heart Fail. 2011 Sep;4(5):669-75. 
29 Miller WL. Fluid Volume Overload and Congestion in Heart Failure: Time to Reconsider Pathophysiology and How Volume Is Assessed. Circ Heart Fail. 2016 Aug; 9(8):e002922.

30 Valentova M, von Haehling S, Bauditz J, Doehner W, Ebner N, Bekfani T, et al. Intestinal congestion and right ventricular dysfunction: a link with appetite loss, inflammation, and cachexia in chronic heart failure. Eur Heart J. 2016 Jun;37(21):1684-91.

31 Horwich TB, Kalantar-Zadeh K, MacLellan RW, Fonarow GC. Albumin levels predict survival in patients with systolic heart failure. Am Heart J. 2008 May;155(5):883-9.

32 Liu M, Chan CP, Yan BP, Zhang Q, Lam YY, Li RJ, et al. Albumin levels predict survival in patients with heart failure and preserved ejection fraction. Eur J Heart Fail. 2012 Jan;14(1):39-44.

33 Arques S, Roux E, Stolidi P, Gelisse R, Ambrosi P. Usefulness of serum albumin and serum total cholesterol in the prediction of hospital death in older patients with severe, acute heart failure. Arch Cardiovasc Dis. 2011 Oct;104(10):502-8.

34 Schrier RW. Blood urea nitrogen and serum creatinine: not married in heart failure. Circ Heart Fail. 2008 May; 1(1):2-5.

35 Sands JM. Mammalian urea transporters. Annu Rev Physiol. 2003;65(1):543-66.

36 SR G. Cellular and Integrative Functions; in Cowley AW LJ-F, Ausiello DA, ed. Baroreflex control of vasopressin secretion in normal humans. New York: Raven Press; 1988. pp. 389-97.

37 Girerd N, Seronde MF, Coiro S, Chouihed T, Bilbault P, Braun F, et al.; INI-CRCT, Great Network, and the EF-HF Group. Integrative Assessment of Congestion in Heart Failure Throughout the Patient Journey. JACC Heart Fail. 2018 Apr;6(4):273-85. 